\title{
Navigating learning worlds: Using digital tools to learn in physical and virtual spaces
}

\author{
David Parsons, Milla Inkila, Jonathan Lynch \\ The Mind Lab, Auckland, New Zealand
}

\begin{abstract}
This article explores the various ways that teachers and learners can navigate different learning worlds with the support of digital tools. Increasingly, teaching and learning takes place in spaces beyond the classroom, whether physical or virtual. Place, navigation and movement have all been recognised as important concepts in approaches to understanding how we learn in and across places. With our postgraduate cohort of in-service teachers from across New Zealand, we have been exploring forms of learning that engage in the exploration of other spaces, using a range of digital tools. Google Tour Builder has allowed creative global navigation in a virtual space, Google Expeditions has given teachers an opportunity to integrate virtual reality into their classrooms, and Actionbound has exposed them to the use and design of situated outdoor learning activities with geolocated augmented content. Our article is based around participant interactions on social media that express their responses and creativity using mobility in physical spaces and the navigation of virtual spaces. Based on these interactions, we reflect on the nature of pedagogy in technologyredefined activities that involve senses of both place and navigation, structuring our analysis along two continua of physical accessibility and the extent of world knowledge.
\end{abstract}

\section{Introduction}

It might be argued that there have traditionally been two learning worlds - those of the "real" world and the classroom - and for a period of time these two worlds failed to suitably collide. It is often asserted that the model of schooling that we have inherited from the last two centuries is based on an industrial, factory model (Robinson, 2008). However, within that batch processing, production-oriented frame, schools and teachers have increasingly embraced the opportunities for further learning possibilities, enabled or enhanced by technology. The potentials of virtual reality (VR) in the classroom, for example, have been discussed for decades (e.g., Pantelidis, 1993), so it is unsurprising that some educators have already taken advantage of these, using cheap and accessible tools like Google Expeditions, which can be accessed through the Google Cardboard viewer (Howard, 2016). Brown and Green (2016) outlined several tools that are relatively accessible to educators, some that, like Google Expeditions, also use Google Cardboard as the viewer (e.g., Streetview) and others that use different VR technologies, such as zSpace and Oculus viewers. Billinghurst and Duenser (2012) described a range of augmented reality (AR) tools that can be used in the classroom, including resources that cross over into VR. Outside the classroom, digital tools that support geolocation can be used for a host of learning experiences. Mobile apps like Actionbound (https://en.actionbound.com/), which make it easy to create AR learning experiences linked to physical locations though satellite navigation, encourage active, exploratory and independent learning (Rittel, 2017). Digital tools do not, however, have to utilise augmented or virtual reality to take the learning experience out of the classroom. Google Tour Builder, which grew out of a Google Earth project, enables multimedia global navigation without leaving the classroom. Using Tour Builder develops geospatial skills and allows for geographical explanations and data synthesis to be integrated into students' work (Macklin \& McCann, 2015). In this article, we explore the different potentials of these learning worlds in a study of New Zealand teachers' social media posts that reflected on experimenting with these tools in their own learning experiences and designing new learning experiences for their students.

Dewey (1938) noted the importance of continuity and interaction in experiential learning; learning environments should not be restrictive but fit into a broader social world. Contemporary digital tools now enable us to enhance and augment experience in physical spaces and create new experiences in virtual spaces, brushing many of the traditional restrictions of the classroom aside. These tools empower learners and educators to navigate, augment and simulate multiple learning worlds. These learning worlds might be considered as comprising "inside" and "outside", or they could be seen as less dualistic, where topographical location is only one of the pedagogical concerns. Leander, Phillips, and Taylor (2010) describe the contemporary classroom as "an imagined and expanding geography" (p. 330), critiquing how concepts of place, trajectory and network break open the enclosed classroom. The place of learning is no 
longer a single container but comprises multiplicities of experience. In this paper we seek to investigate the pedagogical impact of practicing teachers' use of digital tools in the classroom with a focus on space and place. This research also had an impact on the researchers, where we were drawn to consider the complexity and messiness of teacher adoption of such tools in the classroom within a view of place that is not dualistic, and this shift in our thinking has made us consider future research in this domain.

\section{Pedagogical issues in learning worlds}

Pedagogies that foreground space and place are well established in education that occurs outside the classroom (Beames, Higgins, \& Nicol, 2012; Hill \& Brown, 2014). In New Zealand, education outside the classroom is a developing field of practice that incorporates place as an important pedagogical feature (Brown, 2012; Cosgriff, 2015, 2016). More generally, space and place are seen as important in education (Edwards \& Usher, 2000). This has been asserted because place is primary to human experience (Casey, 1997) and because education is arguably always situated (Ellsworth, 2005; Noddings, 2012).

The way we came to understand the significance of "place" in learning changed throughout this project, and we explore our findings from two perspectives that have emerged. We originally set out to undertake this research from within a dualistic and Cartesian understanding of place and space. This was through our initial understanding of the pedagogical importance of a distinction between a virtual world and a physical world. However, the findings and discussion show that through the undertaking of this research we have challenged our original position of understanding place and space as dualistic. Our move towards continua in the findings, and discussion, were some of the ways we responded to these different understandings of place and pedagogy with digital technologies that this research has opened for us. This move to understanding place as not dualistic foregrounds the importance of place and the relations we enter into; we are always in places, and those places are fundamental to all our experience as humans (Casey, 1997). Casey posits that we are always somewhere, not just anywhere, and that our local operations are how we make sense of our emplacement, "Thus the absolute [the abstract] has become the local" (p. 305). In other words, place is about our relations with the local and the practices we undertake there.

Our shift towards this understanding of place is also informed by shifts that are being reflected in postmodern educational research. Some researchers reject dualistic views of place and are informed by theorising of space in social theory, where place is relational and hybrid (Edwards \& Usher, 2000; Fenwick, Edwards, \& Sawchuk, 2011). Taking a view of education and information and communications technology (ICT) within a relational frame has implications for richer understandings of practices that accommodate the messiness of teaching and learning with ICT (Al-Mahmood, 2008). Continuing in this line of thinking, Nespor (2003) offers an example of this when he argues that meaning making with course materials is a spatial configuration as well as a discursive one. This understanding of space, place, and learning as somehow interconnected, enmeshed if you will, has important pedagogical implications for learning and planning learning. For example, our planning might only consider the artefacts (e.g., slide presentations) but not the places or spaces they are used to teach in. Edwards and Usher (p. 76) note that ICT and future educational practices will be strongly influenced by the spatial changes that new technologies offer education. The boundaries of the school buildings will become diffuse and pedagogies will need to change. How do we consider these new technologies and changes in pedagogy they might engender? If, as Edwards and Usher suggest, different ways of being in place result in different meanings, how do we accommodate these ideas practically? Research on mobilities and learning technologies offer some details to consider here.

In their analysis of new learning mobilities and the role of technologies within them, Leander et al. (2010) focus on the growth in the pervasiveness of mobile devices and social networking. Certainly, these technological trends impact on ideas about where and how learning takes place, but there are also more specifically space-related technologies that expand out from the idea of classroom as container. Milgram, Takemura, Utsumi, and Kishino's (1995) reality-virtuality continuum outlined the relationships between virtual and augmented reality within an overall context of mixed reality (MR). The authors went on to outline a number of other important criteria for classifying MR systems, including the degree of ability of the viewer to manipulate objects in the system. A further concept introduced in the article was the extent of world knowledge, which defines how much we actually know about objects and the world in which they are displayed. Although the authors define this conceptualisation from a technical perspective, it also 
usefully matches to an educational view of MR, whereby some learning experiences are based on constructing new knowledge, while others are based on sharing existing knowledge.

The challenge for educators is to identify the appropriate learning goals and pedagogies that can be integrated into the use of such tools. What transferable skills and knowledge can be gleaned, for example, by a student wearing a VR headset to experience images from a distant location? What are the expected learning outcomes from guiding students through outdoor waypoints to gather data? What is the extent of world knowledge assumed before the activity, and what is the knowledge gained as a result of the experience?

There are also a number of pitfalls to be aware of when opening up learning into new augmented and virtual spaces. Fitzgerald et al. (2013) highlighted a number of potential issues with using MR tools for learning. Information overlays may reduce observation skills by offering excessive scaffolding and reinforcement, while excessive overlays may cause cognitive overload. User-generated content may also be of variable quality. Enriquez (2011) noted the limitations of top-down approaches to mobility (such as field trips and museums), which ignore the "counter-scripts" of the learners' own mobility patterns. Although we do not explore these questions and challenges in detail in this article, since each one would require extensive examination, we explore the contexts within which they may arise. The background investigation for this study raised questions such as:

(a) How important is it that a learning activity is enacted in a real place?

(b) What is the role of place in terms of digital learning activities, which again may take place in either physical or virtual worlds?

One answer might lie in the way that some authors and researchers understand places as pedagogical. Places can be pedagogical in the way that they encourage learning that is co-constructed between teachers, places and others (Waite, 2011). This relational view means that opportunities for learning are opened up and cocreated as places are encountered in both real and virtual worlds. For example, research that has investigated place and pedagogy in the primary geography curriculum in the United Kingdom found that through place, and learner agency, students and teachers co-constructed their curriculum and learning (Catling, 2013; Lambert \& Biddulph, 2015). Understanding learning worlds as real or virtual is something we return to in the discussion, where our thinking evolves into a less separatist view. In doing so, we offer more nuanced ways to see the potential of mixed reality for learning in places, both inside and outside the classroom.

\section{Research context}

The context under discussion in this article is an in-service postgraduate program for New Zealand teachers that enables them to transform their practice using digital and collaborative learning. Although there is significant course content that is situated within the classroom, some learning experiences take place in spaces beyond the classroom. Some of these learning spaces are physical (i.e., outdoor environments) and some are virtual (i.e., MR). A further learning experience is the recollected or imagined journey.

There are many software tools that embody a sense of place, real or imagined. Which ones are more likely to have pedagogical value depends on the context of learning and the characteristics of the learners. A further concern is the accessibility of software tools and related hardware, such as VR headsets. Our choice of tools for the activities reported on in this article was based on an intent to provide a broad range of placerelevant learning experiences using easily accessible, low-cost tools. Using GPS-enabled applications, we have been exposing students to the use and design of situated outdoor learning activities that can be created for accessible outdoor spaces. Using VR, we have given students an opportunity to integrate distant worlds into their classrooms, while mapping and exploration tools allow creative global navigation in a virtual space. The purpose of this article is to seek to examine the nature of these learning experiences through an analysis of the students' social media posts, and to consider what future research direction we should take.

To provide a context within which we might integrate learning that takes account of place into the classroom, we selected the following tools: Actionbound (for outdoor location-based augmented reality), Google Expeditions (for VR) and Google Tour Builder (for augmented map-based learning). Actionbound is a simple tool that makes it possible to quickly create learning activities through which students can navigate using QR codes or GPS locations. Various activities can be configured to take place at these 
locations, such as answering questions or taking photos or videos and capturing these with the app. Google Expeditions is a tool that can be used with the Cardboard VR viewer in a team context, where one member takes the role of guide and others take the role of virtual explorers. The VR experiences provided by Google Expeditions are collections of 360 degree and/or 3D images annotated with further information. Custom educational content is being created with various partners, and teachers can create their own trips and upload them to share (Google, 2019). Tour Builder is an interesting tool that was originally created for Google Earth to give veterans a way to record where military service has taken them, to preserve their stories and memories (Google, 2018). It differs from creating flythrough tours in Google Earth since it runs independently of Google Earth in the browser and makes it easy to add photos and videos to a tour sequence and share these on social media.

There are clearly some advantages to designing learning with digital activities that are grounded in realplace experiences as these bring together aspects of real-world learning as noted in the ITL rubric for 21st Century Education (Microsoft Corporation, 2012). The rubric emphasises that real-world learning should involve solving real-world problems, and also innovating, so it is important that experiences of place in education are designed to allow for innovation. Learning outside the classroom is invaluable for developing creative and entrepreneurial qualities (Zhao, 2012), but we should consider to what extent this has to be physically outside the classroom, as opposed to being experienced in virtual spaces. Innovation is sometimes easier in virtual or augmented environments than in purely physical ones.

\section{Method}

Data were gathered for this study from social media posts made by our students (i.e., teachers enrolled on the course) relating to the use of tools relevant to an analysis of learning worlds. A low-risk notification was made to the institutional ethics community stating that data collection would be anonymous and that student participation in posting data was informed and optional. Relevant student posts were gathered from Google Plus online communities, where students voluntarily share their professional interactions with other members of the course and their facilitators. No personal posts are made to these communities, which are intended as professional online communities of practice. In many cases, the posts made to the course Google Plus community page are links to the students' public, professional course blogs. Many of the posts are collaborative. Postings from three cohorts, consisting of around 1000 students, were analysed. From these posts, we identified 152 that contained relevant insights for this particular study, by referring to the tools we were investigating and the concept of navigation. This data, which was aggregated and anonymised, was qualitatively analysed for ideas and themes related to different aspects of learning worlds and the nature of navigation within them. Our coding approach was initially open. We took each post and summarised its core learning space. Then we identified groups of related posts that addressed similar learning spaces. For example, the category "cultural journeys" was used to group together activities based around iconic New Zealand experiences such as the journey of the ANZAC soldiers to Gallipoli. The next phase of coding was axial, based on two modified continua from Milgram et al. (1995); a physical accessibility and learning spaces continuum (based on the reality-virtuality continuum) which captures the extent to which learning can take place in real-world contexts, and an extent of world knowledge continuum, which we adapted to consider to what extent a learning activity relies on existing or new knowledge. We describe these continua in more detail in the following sections.

\section{Physical accessibility continuum}

Figure 1 describes the continuum of physical accessibility, where some learning activities are simple to host in an augmented physical space, while others are difficult or impossible, and would require a virtual learning space. 


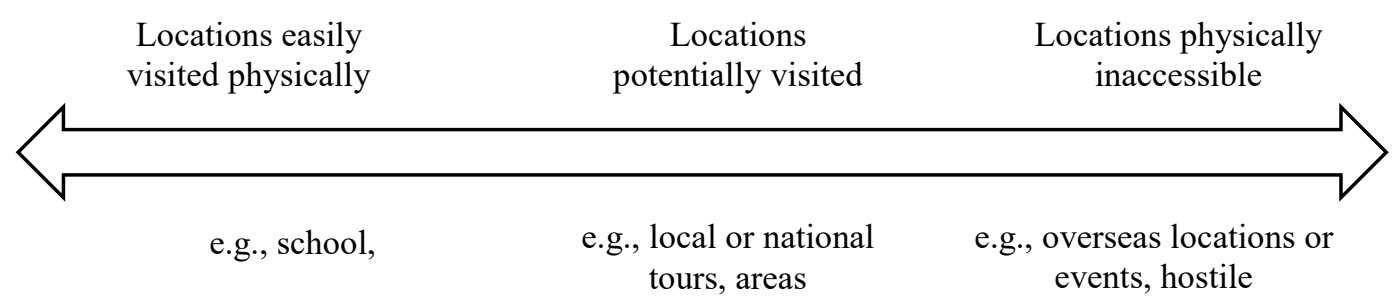

Figure 1. The continuum of physical accessibility in learning spaces

The continuum of physical accessibility in learning spaces leads to very different technological and pedagogical solutions for different levels of accessibility. Tools like Actionbound, which enable learners to explore augmented, geolocated, real-world contexts, are of necessity based in locations that are easily accessed. Examples from the data are typically sited around schools, or at least localities. Where locations are physically inaccessible for most or all students, because of the costs or potential risks involved in visiting such locations, VR tools such as Google Expeditions can provide immersive learning contexts. Between these two extremes, tools such as Tour Builder can involve either local tours that could be physically undertaken, or much more distant itineraries that serve different educational purposes. Thus, the sense of place, whether physical or virtual, is supported from a learning perspective by a diverse range of digital tools. Although not core to our discussion, the concept of affordance has some role to play here. Physical learning spaces that are being augmented by technology can be explored by leveraging the affordances of in situ devices (Parsons, Wishart, \& Thomas, 2016). In contrast, the ability of a VR tool to facilitate experiential learning tasks that would be impractical or impossible to undertake in the real world is an affordance in itself (Dalgarno \& Lee, 2010).

\section{Extent of world knowledge continuum}

The second continuum (Figure 2) relates to the extent of world knowledge. In this article we reinterpret this concept from its original technical definition (Milgram et al., 1995) to one that questions to what extent students are recording the known, or discovering the unknown, in different learning spaces. The role of affordance in this continuum is primarily focused on the extent to which different digital tools enable the creation or transmission of content.

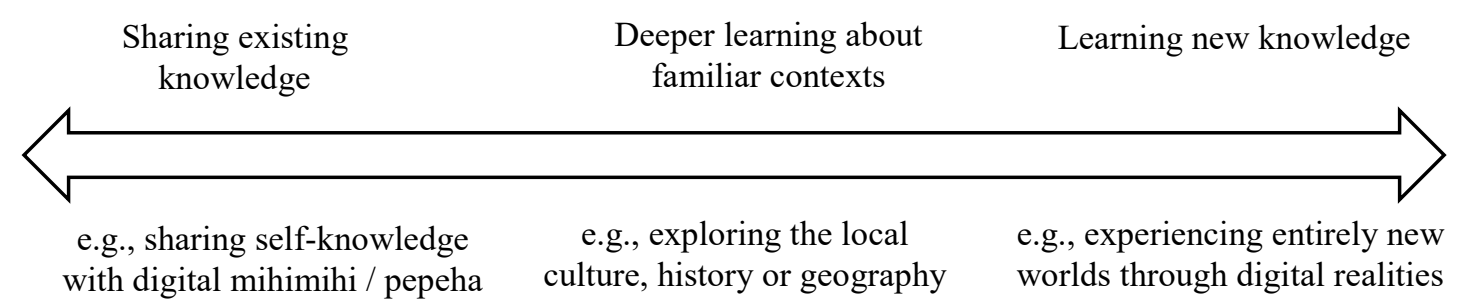

Figure 2. The continuum of extent of world knowledge

The continuum of the extent of world knowledge is based on how much pre-existing knowledge the learner brings to a given learning world. In some cases, digital tools are used to record and share personal knowledge that is already well known to the self, but in sharing with others may become more socially understood. At the other end of the continuum there is the experience of entirely new learning worlds, where little or no knowledge is pre-existing, for example, a virtual tour of an environment never before explored. In some cases, digital tools are used to enhance knowledge that is partly familiar, for example, local culture, history or geography, where AR tools can help to provide a deeper understanding of the familiar world. 
In terms of real-world knowledge within a relational view of place, we see that there are possibilities for digital technologies to enhance partly familiar knowledge, and there is room for more nuanced understandings here. In a relational worldview, we might ask other questions of this data. For example, what features of real-world knowledge do virtual technologies hide or obscure? Some real-world knowledge that is reliant on the visual may be learnt, but what about that which is less visual? The virtual tool will bring us into certain relations with the places we see in the technologies, but what other relations are we intertwined with and what pedagogy is influenced? We might consider what configurations of technology, imagery and location the virtual experience is taking place in, to further understand learning in this area.

In applying these continua to our analysis, we first analysed each type of tool use separately: augmented map-based navigation, outdoor navigation using location-based tools and virtual navigation in immersive online spaces. For each tool we then mapped the learning activity types against both continua to explore how these two continua interact in teaching and learning that is situated in space and place.

\section{Results and analysis}

In this section we present an analysis of the data in three subsections, one for each of the three applications that were investigated: Google Tour Builder, Actionbound and Google Expeditions.

\section{Google Tour Builder}

The most popular tool in terms of community posts was Google Tour Builder. It was clear that the tool inspired many ideas for how it could be used in the classroom. Since Tour Builder enables the whole world to be virtually accessed and interacted with, it is unsurprising that many of the suggested learning activities were about creating new knowledge in physically inaccessible spaces. Important in some of these activities is the absolute nature of inaccessibility. For example, visiting the seven wonders of the ancient world can only be done virtually, even if one were to travel to their former locations, since all have disappeared, save the pyramids. Others might prove hazardous to visit in person, such as earthquakes and volcanoes, or certain areas of child poverty (e.g., war zones). One of the more imaginative suggestions asked students to pick some types of Pokemon and identify new places that could be used in the game by taking an approach based on biomes, whereby plants and animals with common characteristics are found in different areas with similar climates.

At the other end of the scale were student experiences that were often shared by many peers, such as school camps. In these situations, the physical locations were known to the participants, and the activities included sharing experiences of familiar knowledge. Several other tours were based on the New Zealand Māori concept of the mihimihi/pepeha, whereby individuals introduce themselves to a gathering and include the important places and the life journeys that have brought them to where they are today. Activities designed around this concept were often approached in a collaborative manner so a single "tour" would include the journeys of all members of the class. These tours might move beyond locations that are easy to visit, but would often be located in known and accessible locations.

Amazing Race-style tours were also favoured, integrating clues and tasks (such as budgeting) with navigating outdoor locations. This clearly overlaps in style with the geolocated outdoor activities that were also undertaken in the course. Contexts for these varied, but one example was related to Auckland city's infrastructure issues. Several submissions related to specific geographical areas and features of New Zealand that would have been relevant to students in those locations, such as the Canterbury rivers (on the East of New Zealand's South Island) and the Wairarapa (an area in the South East of New Zealand's North Island). A broader national issue that was tackled was earthquakes (where they have occurred, relationships between them, their long-term impact on tourism, transport) - at the forefront of the experience of many in New Zealand.

Some of these were simple tourist itineraries such as the classic New Zealand Tiki tour (taking a roundabout route to a destination, if indeed there is any destination at all), although these were not simply lists of locations but also included learning activities, such as calculating overall costs, explaining reasons for visiting certain locations and representing these with appropriate artefacts. Some were explicitly themed to subject areas, such as a tour of architectural shapes. A number of world tour itineraries were included, some 
to record actual journeys by students and teachers, and others to plan possible journeys, including tasks such as language learning. A number of submissions related to the Rio Olympics, which was topical at the time when we explored Tour Builder with one of the cohorts. While many of these were simply about getting to Rio, or the journey of the Olympic torch, one of the more interesting submissions asked students to consider where the various teams were training, and why these locations had been chosen for those sports.

New Zealand culture and history played a significant role in many of the ideas, for example, the journey of New Zealand ANZAC soldiers to Gallipoli in World War 1, the haerenga (journey) of Maui through Aotearoa (New Zealand), and following in the footsteps of Sir Edmund Hillary. We placed these cultural journeys firmly in the middle of the continua, in that they are both deeply familiar to a New Zealand audience but also open to much further learning, with both local and distant contexts. We might contrast this placement with less familiar New Zealand histories of the Otago Gold Rush or significant disasters, where learning new knowledge is more to the fore.

In the next two figures we present two indicative examples of different types of journey. Figure 3 is typical of those that related to specific locations and shows a tour of seven natural wonders of the world, where students were encouraged to "use your senses to describe your location so that we have the feeling of being there".

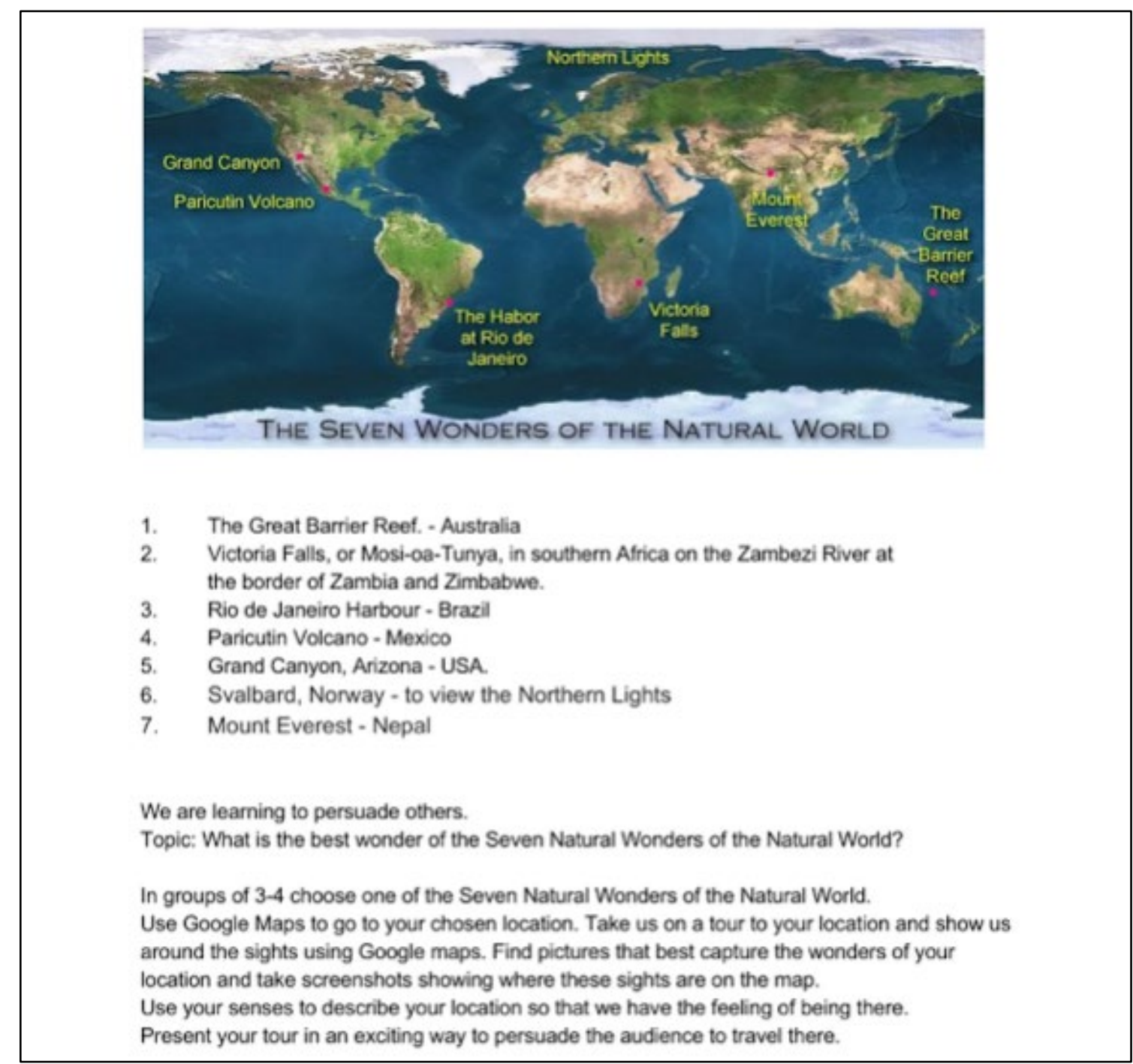

Figure 3. Student social media post suggesting a Google Tour Builder activity based on seven natural wonders of the world 
The post shown in Figure 4 represents the more imaginary journeys, inspired here by a work of fiction, Roald Dahl's Esio Trot, in which a distance of a million miles is mentioned. In the suggested activity, students would consider where they might end up after a million miles, and also consider whether travelling a million miles was even realistic.

\section{Esio Trot: Google Tour Builder Activity}

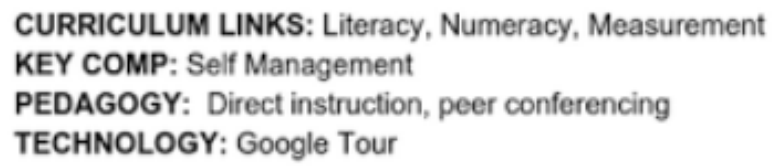

You must:

- State where you would travel to on your tour

- What you might do at destination, include photos and relevant information

- Know how many miles each part of the journey is

- Convert your miles to kilometres because this is the unit of measurement we use in New Zealand

\section{Extension:}

- Compare the journey with how our ancestors would have travelled (time, access to countries, transportation)

- What might happen in the future?

- Compare the risks from traveling now to when our ancestors travelled.

Figure 4. Student social media post suggesting a Google Tour Builder activity based on Roald Dahl's Esio Trot 
Figure 5 provides a mapping of the various ideas that emerged from our analysis of learning activities designed for Tour Builder, grouped into relevant categories, against the two continua of physical accessibility and extent of world knowledge.

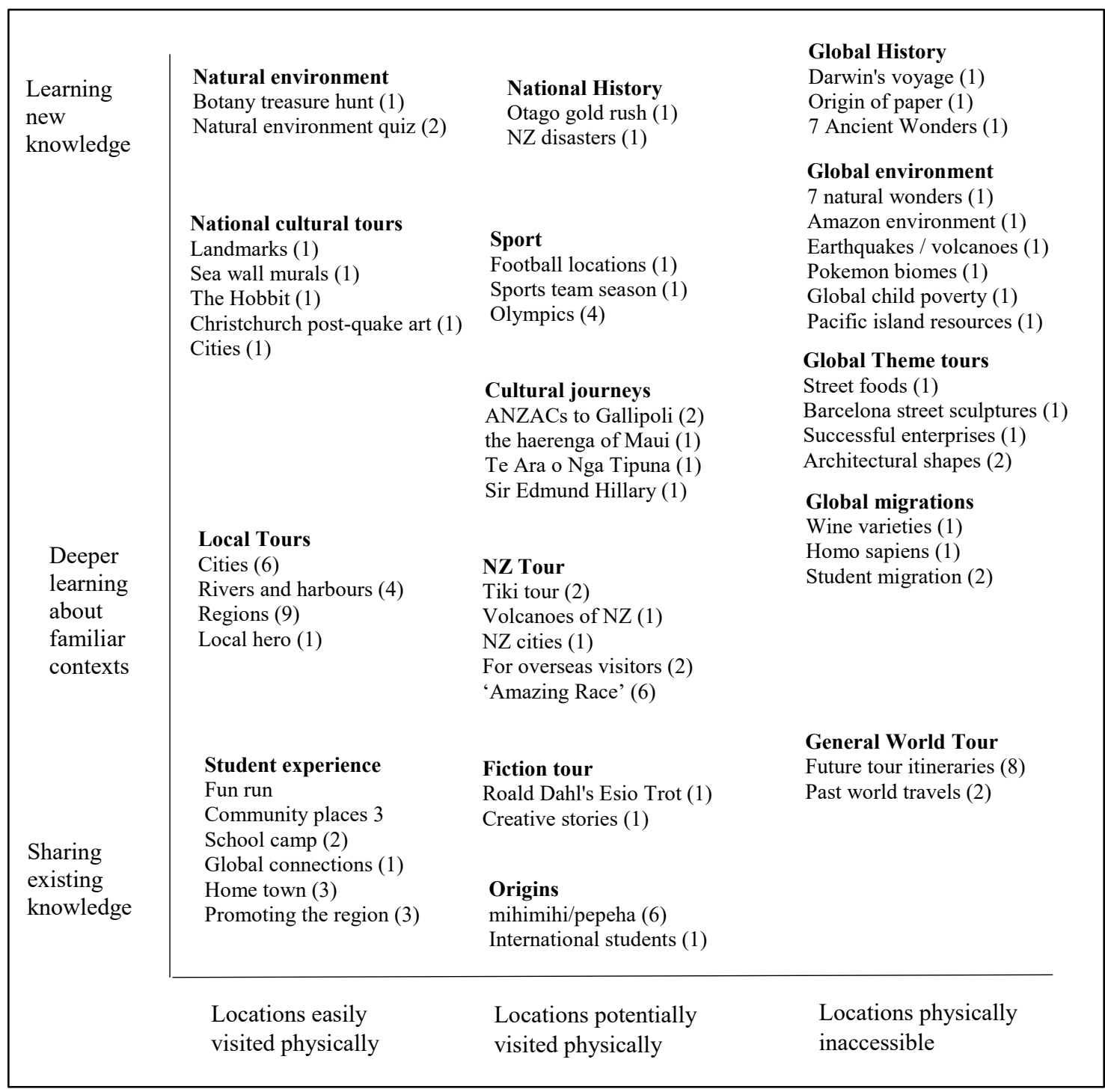

Figure 5. Tour Builder activities mapped against the continua of physical accessibly and the extent of world knowledge.

\section{Actionbound}

Posts relating to the use of Actionbound were also relatively well represented. A common theme of those that were found was to help new students navigate their way around their schools and identify important locations. One of the non-school examples created by the students asked users to identify places to buy food at specific locations. Depending on the area, this could provide a rich source of cultural discussion. Another example was based on navigating through a culture walk. Two groups created explorations based on fostering hauora (well-being) while another activity focused on linking up with other staff members at cafes for specific activities. Learning designs that are based on navigating "real" spaces resonate strongly with the concept of situated cognition, where knowledge involves the activity, context, and culture in which it is developed and used (Brown, Collins \& Duguid, 1989). Although our data set was very small, it amply demonstrated these concepts: activity (e.g., buying food), context (e.g., school) and culture (e.g., culture walk). 
One particularly interesting example, which is categorised under cultural understanding, is based on a recreation of a story about a young Sudanese girl fetching water. The outline design of the navigation, for implementation using Actionbound, is shown in Figure 6. This type of overlaying of a virtual story onto a real-world location is redolent of situated learning activities such as "invisible buildings", where fiction augments physical places (Winter \& Pemberton, 2011).

\section{To get an idea of how easily we get water and to get some idea of the challenge the young Sudanese girl in our shared story faced \#hamilton \#gameflowchart}

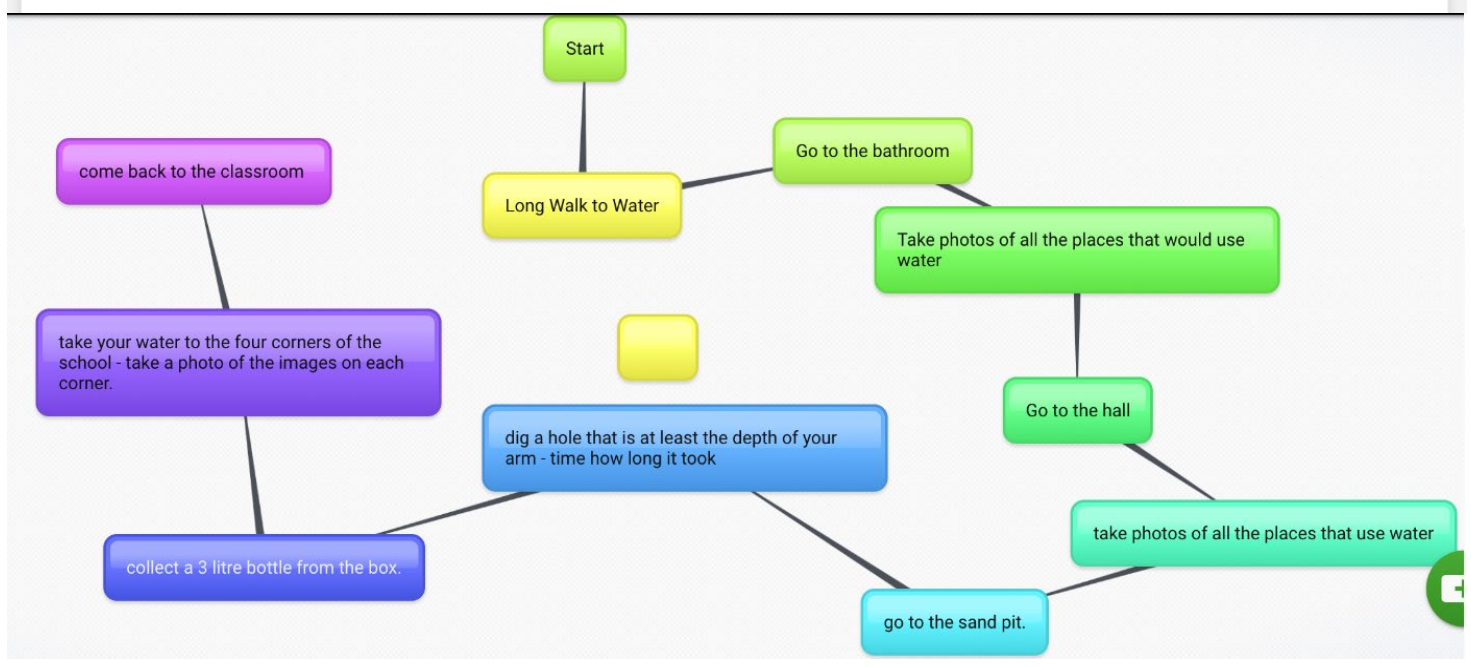

Figure 6. An outline design for an Actionbound activity based on a Sudanese girl's search for water

Figure 7 shows the Actionbound activity types we identified from the data positioned against the two continua. 


\begin{tabular}{|c|c|c|c|}
\hline $\begin{array}{l}\text { Learning } \\
\text { new } \\
\text { knowledge }\end{array}$ & $\begin{array}{l}\text { Local Orientation } \\
\text { School familiarisation (10) }\end{array}$ & $\begin{array}{l}\text { History/geography } \\
\text { Industrial archaeology (1) }\end{array}$ & $\begin{array}{l}\text { Non geolocated content } \\
\text { Interacting with policies (1) }\end{array}$ \\
\hline $\begin{array}{l}\text { Deeper } \\
\text { learning } \\
\text { about } \\
\text { familiar } \\
\text { contexts }\end{array}$ & $\begin{array}{l}\text { Generic challenges } \\
\text { Geolocated treasure hunt (1) } \\
\text { Geolocated challenges (5) } \\
\text { Natural environment } \\
\text { Botany treasure hunt (1) } \\
\text { Natural environment quiz (2) } \\
\text { Local Orientation } \\
\text { Finding stationary (1) } \\
\text { Cafes (1) } \\
\text { Games } \\
\text { Hunt the chickens (1) } \\
\text { Game of life (1) } \\
\text { Arithmetic game (1) } \\
\text { Practical activities } \\
\text { Worm farm game (1) } \\
\text { Beautifying school (1) } \\
\text { Rubbish and recycling (1) } \\
\text { Mission day map (1) }\end{array}$ & $\begin{array}{l}\text { Art History } \\
\text { Gallery tour (1) } \\
\text { Specific skills } \\
\text { Photography (1) } \\
\text { Geoskills (1) } \\
\text { Learning about fingerprints (1) } \\
\text { Science experiment (2) }\end{array}$ & $\begin{array}{l}\text { Language } \\
\text { Japanese language tasks (1) }\end{array}$ \\
\hline $\begin{array}{l}\text { Sharing } \\
\text { existing } \\
\text { knowledge }\end{array}$ & $\begin{array}{l}\text { Locations easily } \\
\text { visited physically }\end{array}$ & $\begin{array}{l}\text { Locations potentially } \\
\text { visited physically }\end{array}$ & $\begin{array}{l}\text { Locations physically } \\
\text { inaccessible }\end{array}$ \\
\hline
\end{tabular}

Figure 7. Actionbound activities mapped against the continua of physical accessibly and the extent of world knowledge

\section{Google Expeditions}

There were few posts relating to the use of Google Expeditions. Apart from some acknowledgement that students could more directly experience places around the world, rather than just looking at pictures, there were few pedagogical suggestions, although those that tried it out with their students or colleagues reported a very enthusiastic reaction. However, one post suggested using this tool as a precursor to a video call with a class overseas, a way of becoming familiar with the other students' context before meeting (virtually) with them. Some teachers reflected that it was easier and more directly useful to implement AR in the classroom, since AR could be used to overlay relevant resources to parts of a school and provide in-context learning, such as Te Reo Māori words and phrases, or students providing their own augmented photo walls. Perhaps the key feedback from the use of Google Expeditions was that it had huge potential for the future, as outlined in this student's social media post:

We believe that the Expeditions app is closest to the "sweet spot" out of all the apps we have tried tonight... This app would open up the world in all subjects and take you to places you may not be able to take your class to. Even if you already have the content knowledge, the app offers even more for you with the prompts at each point, and follow up questions too for your students! It covers many of the ITL rubrics too - collaboration, knowledge construction, use of ICT, solving real world problems.

It was clear, however, that using pre-created content in Google Expeditions was not leading to constructivist forms of learning. As with many other software tools, it works at multiple levels. Using pre-created content can be a first step in learning with such environments, but for them to embody effective pedagogy, educators and students need to be able to create their own content, in virtual spaces related to them. A similar context appears with virtual world tools, where learning depends on specially constructed environments that are 
relevant to specific learning goals (Parsons, Stockdale, Bowles, \& Kamble, 2008). The barriers to entry, however, include the cost and complexity of using such tools. Referring once again to the Real World Learning rubric (Microsoft Corporation, 2012), a tool that makes it difficult to innovate does not fully support real-world learning. Fortunately, since we ran the sessions that informed this article, Google have given access to the Tour Creator tool that allows teachers to create their own expeditions (Perez, 2018).

\section{Discussion and future work}

Our study has raised a couple of questions around the relationship between pedagogy and learning worlds, both physical and virtual. One question was: How important is it that a learning activity is enacted in a real place? A subsequent question was: What is the role of place in terms of digital learning activities, which again may take place in either physical or virtual worlds? With regard to the first question, it is notable that, whether or not the learning activities designed by our students were based in physically accessible locations, they were nevertheless real places. This is in the sense that if, for example, teachers designed a learning activity using Tour Builder that related to the Olympic Games, although the students would not be enacting their learning in that real place, the learning would nevertheless be based on the realities of that place, such as students looking at why different sports teams based their training camps in different locations. Another aspect to consider is the way that learning activities were often designed to take place in familiar geographies, even if the learning itself was set in a virtual representation of that geography. Thus, the learning can take the role of either an understanding of a known context or a trigger for interpreting future experiences, but we consider it significant that a number of learning activities were located in these nearby geographies. We are also drawn to consider what role these technologies play in the affective domain and what pedagogical strategies are important for us to use them to educate in this area

The first question in this discussion is also an ontological and epistemological one. How we understand place will impinge on how it will be considered in any pedagogy. For this research, we came to see that the issue is not about whether a place is real or virtual as both can be pedagogically useful or important; the real and virtual are not so separate. This is in line with emerging socio-material orientations to educational research. Fenwick et al. (2011) argue that digital technologies and ICT create spatial experiences that are "real" (p. 139) enough to be pedagogically important. In other words, the dichotomy of real/virtual is not useful in any pragmatic understanding of how our lives are intertwined with technology, ICT or virtual experiences. Fenwick et al. note that the techno-spatial configurations of our day-to-day lives, our material worlds, successfully accommodate virtual worlds or cyberspace. Pragmatically, we can understand them to not be separated but relationally intertwined. The result of this view is that virtual experiences can be pedagogically useful because the virtual world is not separate from any other world. Al-Mahmood (2008) argues for taking a relational view of the ontological situation in her research on identity, spatiality and online learning spaces. Al-Mahmood argues for an understanding of the social-material as where the multiple intermingling of materials, people, artefacts texts, etc., are all involved in how we make sense of the world. She argues that we need "to view spaces/places as dynamic and emergent" (p. 19). The result of these views is that what is important pedagogically are the new networks, new configurations and new possibilities for learning about the world through the digital and virtual worlds we enter into (Fenwick et al., 2011). We see the strengths of the continua we offer here as ways of understanding what new possibilities might come about through the virtual worlds we encourage our learners to engage with. The continua allow for consideration of the relational and networked features of places and the new relations that might be produced. What we did notice was the possibilities that the digital components brought to these understandings.

In terms of the second question, it would be reasonable to conclude that the digital component was essential to the experience in every case. Most of these activities would have been impossible without the digital tools. Certainly, the VR experiences could not be replicated in other ways. Learning activities that involved augmenting the real world, such as geolocated, GPS-enabled learning journeys could of course be replicated to some extent without digital tools, but with much less richness and interactivity, and with considerably less opportunity for participants to co-create content. Tour Builder at its simplest is just navigating across maps. However, again, the richness of the tool itself and the ability to integrate a range of multimedia makes it far more pedagogically valuable than a non-digital solution. We see from these examples that pedagogies of place are potentially greatly enhanced by the appropriate integration of suitable tools that meet pedagogical aims and objectives. These points also allude to the interconnectedness of places to the 
pedagogy and suggest that the delineation between real and virtual is less of a distinction and more about certain relations and capacities coming into being that enrich education and learning.

Finally, we should not leave the discussion of learning worlds without recognising the importance of students having the opportunity to share their self-made products with others online. In each of the activities described in this article, regardless of the tools used, our students linked evidence of their learning with their online Google Plus community. By doing this they made the learning impact wider, as indeed their own students can when they use these opportunities. By using such tools, and sharing their creations, they provide real learning to people outside their own circles, making it more real and open to those beyond their classroom. For physical accessibility - within a relational view of place - how might these digital tools contribute to, and foster, a sense of place? These tools provide a visual and cognitive experience of place but are there affective dimensions being missed? We know that affective responses and dimensions to "place experiences" are powerful pedagogical dimensions (Somerville, Davies, Power, Gannon, \& de Carteret, 2011; Somerville, Power \& de Carteret, 2009) and these can be especially important for linking experiences to ethics of care for places (Wattchow \& Brown, 2011). We suggest further research in how AR and VR include or exclude the affective domain in pedagogy.

We have seen from our two continua that there are many combinations of physicality and world knowledge, each of which can provide valuable learning experiences. These are all reinforced by the shared learning space of online communities of practice. In seeking to take advantage of the new worlds being constantly opened up by technology, the challenge for educators is to identify the best tools and pedagogical approaches to meet the required learning outcomes. As well as this, educators might choose to develop strategies to harness learning that emerges through the interconnections with technologies and place. This might include harnessing with any unplanned place relations that we enter into. For example, virtual experiences of places that are physically inaccessible may produce new place relations that are pedagogically important, such as children's affective responses to "witnessing" a rainforest through a VR headset for the first time. We hope that the continua and examples outlined in this article will provide some assistance in making these decisions. Although our data set is somewhat limited, it does provide us with some interesting insights into how our students have interpreted the potentials of location-based learning. whether physical or virtual, as applied to their own particular teaching and learning contexts.

A third continuum that we considered in our analysis relates to the scripts and counter-scripts of learning spaces (Figure 8); to what extent material is generated by teachers or students, and the implications of using those sources (Enriquez, 2011; Fitzgerald et al., 2013). We felt unable to apply this continuum to our own data set, since the suggested activities discussed in our social media community of practice were focused on activities created by teachers for students.

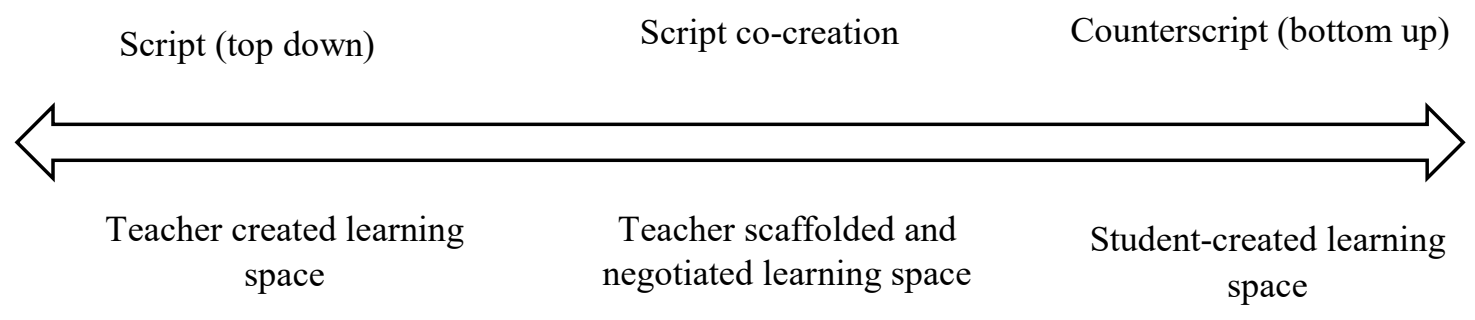

Figure 8. The continuum of script and counter-script

In the continuum of script and counter-script there is a potential tension between learning worlds that are created by educators for consumption by learners, and those worlds that are created by learners for themselves and for their peers. The nature of some tools is that they require a structured content-creation process, possibly by third parties, rendering both teachers and students as consumers of tools such as Google Expeditions. Although there is the potential for these to be created anew, in simpler learning spaces students can create their own content more easily. In a tool like Actionbound, for example, students can simply create their own geolocated learning experiences. However, perhaps the most valuable learning experiences can take place where there is script co-creation, where teachers provide the minimum scaffolding and content is negotiated between all the stakeholders in learning, fostering collaborative innovation. In terms of affordance, the perceived potential of a context to enable creativity cuts across a range of related 
affordances such as interaction with the interface and contextual, active learning (Parsons et al., 2016). Further, as Glăveanu (2012) suggests, creativity can generate new objects with novel affordances.

In terms of script and counter-script we might ask new questions from a relational world view. The cocreation is not being mediated and produced only through the humans in this continuum, so how do certain technologies play a part in any co-creation? Do some technologies facilitate co-creation more so than others? Does Actionbound allow for co-creation pedagogically in a useful way? We consider these questions through offering areas for further research. We suggest these questions could be usefully explored by taking seriously the role of these technologies as being able to impinge on pedagogy in very real and material ways. Harnessing views of less human-centric understandings of agency could be useful in future research to answer these questions. Some educational research has been done that draws on relational and new materialism (Charteris, Smardon, \& Nelson, 2017; Hultman \& Lenz Taguchi, 2010). Employing similar new materialist resources (Coole \& Frost, 2010), where matter and discursive relations are seen as crucial to any understanding could be helpful. For example, Charteris et al. (2017) see that taking a relational view of learning spaces in classrooms and how they can be seen as pedagogical means understanding that the "dynamism of these spaces are coproduced though the complex affective flows of human bodies, acoustics, airflow, textures, lighting, furniture and non-human creatures.” (p. 819). In terms of future research, we suggest that linking the technology and pedagogy in relational interchange might be a useful direction for further understanding what we are touching on here.

\section{Conclusions}

In this article we have explored concepts of space and place alongside the use of digital tools for navigating different types of learning worlds. We have analysed data gathered from social media posts created by inservice teachers reflecting on how they might use these tools in practice. We have presented this data using a combination of open and axial coding to explore the significance of both physical accessibility and the extent of world knowledge in understanding how space and place based digitally supported learning can be enacted. Our results suggest that potential learning worlds might stretch across both continua of physical access and extent of world knowledge, and that in most combinations of these two axes, valuable digitally supported learning experiences can be designed. By placing the data on these continua, we acknowledge the complexity of space- and place-based learning and the many factors that contribute to an experience of place and learning. While we see that some tools such as VR open up new and formerly unimaginable learning spaces, this does not detract from learning that takes place in more familiar and understood surroundings. Rather, the broader potentials of digitally supported place-based learning are emphasised by their evolving contexts of applicability.

\section{References}

Al-Mahmood, R. (2008). Spatialities and online teaching: To, from and beyond the academy. In R. Atkinson \& C. McBeath (Eds.), Hello! Where are you in the landscape of educational technology? Proceedings Ascilite Melbourne 2008 (pp. 11-22). Retrieved from http://www.ascilite.org/conferences/melbourne08/procs/al-mahmood.pdf

Beames, S., Higgins, P. J., \& Nicol, R. (2012). Learning outside the classroom: Theory and guidelines for practice. London: Routledge.

Billinghurst, M., \& Duenser, A. (2012). Augmented reality in the classroom. IEEE Computer, 45(7), 5663. https://doi.org/10.1109/MC.2012.111

Brown, M. (2012). Developing a place-based approach to outdoor education in Aotearoa New Zealand Outdoor ed in our place: “Keepin' it real.”Wellington, New Zealand: Teaching Learning Research Initiative. Retrieved from http://www.tlri.org.nz/sites/default/files/projects/9286_summaryreport_0.pdf

Brown, A., \& Green, T. (2016). Virtual reality: Low-cost tools and resources for the classroom. TechTrends, 60(5), 517-519. https://doi.org/10.1007/s11528-016-0102-Z

Brown, J. S., Collins, A., \& Duguid, P. (1989). situated cognition and the culture of learning. Educational Researcher, 18(1), 32-42. https://doi.org/10.3102/0013189X018001032

Casey, E. S. (1997). The fate of place: A philosophical history. London: University of California Press.

Catling, S. (2013). Teachers' perspectives on curriculum making in Primary Geography in England. The Curriculum Journal, 24(3), 427-453. https://doi.org/10.1080/09585176.2013.801781 
Charteris, J., Smardon, D., \& Nelson, E. (2017). Innovative learning environments and new materialism: A conjunctural analysis of pedagogic spaces. Educational Philosophy and Theory, 49(8), 808-821. https://doi.org/10.1080/00131857.2017.1298035

Coole, D. H., \& Frost, S. (2010). New materialisms: Ontology, agency, and politics. Durham, NC: Duke University Press.

Cosgriff, M. (2015). Snapshots from the field: Transforming outdoor education in the primary school. Set: Research Information for Teachers, 2, 26-35. https://doi.org/10.18296/set.0015

Cosgriff, M. (2016). The reconceptualisation of outdoor education in the primary school classroom in Aotearoa New Zealand: How might we do it? Education 3-13, 44(3), 339-352. https://doi.org/10.1080/03004279.2015.1020440

Dalgarno, B., \& Lee, M. J. (2010). What are the learning affordances of 3-D virtual environments? British Journal of Educational Technology, 41(1), 10-32. https://doi.org/10.1111/j.14678535.2009.01038.

Dewey, J. (1938). Experience and Education. New York, NY: MacMillan.

Edwards, R., \& Usher, R. (Eds.). (2000) Space, curriculum, and learning: International perspectives on curriculum. Greenwich, CT: Information Age Publishing.

Ellsworth, E. A. (2005). Places of learning: Media, architecture, pedagogy. Abingdon, UK: Routledge.

Enriquez, J. G. (2011). Tug-o-where: Situating mobilities of learning (t)here. Learning, Media and Technology, 36(1), 39-53. https://doi.org/10.1080/17439884.2010.531022

Fenwick, T., Edwards, R., \& Sawchuk, P. (2011). Emerging approaches to educational research: Tracing the socio-material. London: Routledge.

FitzGerald, E., Ferguson, R., Adams, A., Gaved, M., Mor, Y., \& Thomas, R. (2013). Augmented reality and mobile learning: The state of the art. International Journal of Mobile and Blended Learning, 5(4), 43-58. https://doi.org/10.4018/ijmbl.2013100103

Glăveanu, V. P. (2012). What can be done with an egg? Creativity, material objects, and the theory of affordances. The Journal of Creative Behaviour, 46(3), 192-208. https://doi.org/10.1002/jocb.13

Google. (2018). About Tour Builder. Retrieved from https://tourbuilder.withgoogle.com/about/faq

Google. (2019). Expeditions Help. Retrieved from https://support.google.com/edu/expeditions/answer/6335093?hl=en\&ref topic $=6334250$

Hill, A. \& Brown, M. (2014). Intersections between place, sustainability and transformative outdoor experiences. Journal of Adventure Education and Outdoor Learning, 14(3), 217-232. https://doi.org/10.1080/14729679.2014.918843

Howard, N. R. (2016, January 5). Come along and ride on a Google Expedition [Blog post]. edutopia. Retrieved from http://www.edutopia.org/blog/ride-on-a-google-expedition-nicol-howard

Hultman, K., \& Lenz Taguchi, H. (2010). Challenging anthropocentric analysis of visual data: A relational materialist methodological approach to educational research. International Journal of Qualitative Studies in Education, 23(5), 525-542. https://doi.org/10.1080/09518398.2010.500628

Lambert, D., \& Biddulph, M. (2015). The dialogic space offered by curriculum-making in the process of learning to teach, and the creation of a progressive knowledge-led curriculum. Asia-Pacific Journal of Teacher Education, 43(2015), 210-224. https://doi.org/10.1080/1359866X.2014.934197

Leander, K., Phillips, N., \& Taylor, K. (2010). The changing social spaces of learning: Mapping new mobilities. Review of Research in Education, 34(1), 329-394. https://doi.org/10.3102/0091732X09358129

Macklin, K., \& McCann, A. (2015). Google's tour builder. Interaction, 43(1), 40-41._Retrieved_from https://search.informit.com.au/documentSummary;dn=128310770499696;res=IELHSS

Microsoft Corporation. (2012). 21st century learning design rubrics. Retrieved from https://education.microsoft.com/GetTrained/ITL-Research

Milgram, P., Takemura, H., Utsumi, A., \& Kishino, F. (1995, December). Augmented reality: A class of displays on the reality-virtuality continuum. In Proceedings of Telemanipulator and Telepresence Technologies (Vol. 2351, pp. 282-293). Bellingham, WA: International Society for Optics and Photonics. https://doi.org/10.1117/12.197321

Nespor, J. (2003). Undergraduate curricula as networked and trajectories. In R. Edwards \& R. Usher (Eds.), Space, curricula, and learning (pp. 93-108). Greenwich, CT: Information Age Publishing.

Noddings, N. (2012). Philosophy of education. Philadelphia, PA: Westview Press.

Pantelidis, V. S. (1993). Virtual reality in the classroom. Educational Technology, 33(4), 23-27. Retrieved from https://www.learntechlib.org/p/170877/

Parsons, D., Stockdale, R., Bowles, J., \& Kamble, V. (2008). If we build it will they come? Creating a virtual classroom in Second Life. In S. Huff \& A. Mills (Eds.), Creating the Future: Transforming 
Research into Practice. Proceedings of 19th Australasian Conference on Information Systems (ACIS 2008) (pp. 720-729). AIS.

Parsons, D., Wishart, J. \& Thomas, H. (2016). Exploring mobile affordances in the digital classroom. In I. Arnedillo-Sanchez \& P. Isaias (Eds.), Proceedings of 12th International Conference on Mobile Learning (Mobile Learning 2016) (pp. 43-50). IADIS.

Perez, S. (2018, May 9). Google's new Tour Creator lets students make their own VR tours. TechCrunch. Retrieved from https://techcrunch.com/2018/05/09/googles-new-tour-creator-lets-students-make-theirown-vr-tours/

Rittel, J. (2017). Actionbound at school: An introduction to library use with Apps \& Co. lSchool Libraries Worldwide, 23(2), 83-96. Retrieved from https://www.questia.com/library/journal/1P41930764371/actionbound-at-school-an-introduction-to-library

Robinson, K. (2008). Changing education paradigms. Retrieved from http://www.cfpscourseweb.com/pluginfile.php/1099/block html/content/RSA\%20\%20Ken\%20Robin son $\% 20$ Lecture $\% 20-\% 20$ transcript.pdf

Somerville, M., Davies, B., Power, K., Gannon, S., \& de Carteret, P. (2011). Place pedagogy change. Rotterdam, Netherlands: Sense Publishers.

Somerville, M., Power, K., \& de Carteret, P. (2009). Landscapes and learning: Place studies for a global world. Rotterdam, Netherlands: Sense.

Waite, S. (Ed.). (2011). Children learning outside the classroom: from birth to eleven. London: Sage.

Wattchow, B., \& Brown, M. (2011). A pedagogy of place: Outdoor education for a changing world. Melbourne: Monash University Publishing.

Winter, M., \& Pemberton, L. (2011). Unearthing invisible buildings: Device focus and device sharing in a collaborative mobile learning activity. International Journal of Mobile and Blended Learning, 3(4), 1-18. https://doi.org/10.4018/jmbl.2011100101

Zhao, Y. (2012). World class learners: Educating creative and entrepreneurial students. Thousand Oaks, CA: Corwin Press.

Corresponding author: David Parsons, david@themindlab.com

Please cite as: Parsons, D., Inkila, M., \& Lynch, J. (2019). Navigating learning worlds: Using digital tools to learn in physical and virtual spaces. Australasian Journal of Educational Technology, 35(4), 144-159. https://doi.org/10.14742/ajet.3675 